\title{
DIAGNÓSTICO DOS PROJETOS DE REFLORESTAMENTO NO ESTADO DO PARÁ NO PERÍODO DE 2008 A 2012
}

Renata Sousa Tenório', Ana Paula Ribeiro Medeiros ${ }^{2}$, Larissa da Silva Soares ${ }^{3}$, Cecília Hernandez Ochoa Coutinho ${ }^{4}$, Denise Nunes Pereira ${ }^{2}$

1 Mestranda, Universidade Estadual do Pará (renatatenorio_@hotmail.com) Belém, Brasil

2 Mestranda, Universidade Federal Rural da Amazônia, Belém, Brasil.

3 Extensionista Rural I, Assistência Técnica e Extensão Rural do Estado do Pará, Viseu, Brasil

4 Gerência de Monitoramento Ambiental, Secretaria de Estado de Meio Ambiente e Sustentabilidade, Belém, Brasil

Recebido em: 08/09/2015 - Aprovado em: 14/11/2015 - Publicado em: 01/12/2015 DOI: http://dx.doi.org/10.18677/Enciclopedia_Biosfera_2015_262

\begin{abstract}
Objetivou-se diagnosticar a situação do licenciamento e demanda dos Projetos de Reflorestamento protocolados na Secretaria de Estado de Meio Ambiente e Sustentabilidade (SEMAS) no período de 2008 a 2012. Realizou-se um levantamento de todos os Projetos de Reflorestamento protocolados nesse período por meio da SEMAS, agrupando os dados a partir da divisão do estado do Pará em seis mesorregiões: Baixo Amazonas, Marajó, Metropolitana de Belém, Nordeste Paraense e Sudeste Paraense e por municípios. No período de janeiro de 2008 a dezembro de 2012, foram licenciados um total de 312 Projetos de Reflorestamento, distribuídos em 57 municípios do Estado. Dentre as seis mesorregiões do Estado, a mesorregião do Sudeste Paraense foi a que apresentou a maior demanda $(67,31 \%)$, contabilizando em 210 licenças neste período. Dos 57 municípios que demandaram por Projetos de Reflorestamento, apenas sete municípios apresentaram demanda igual ou superior a dez projetos de reflorestamento licenciados entre 2008 e 2012 . O município que obteve maior número de LAR's emitidas foi Dom Eliseu, localizado na Mesorregião Sudeste Paraense.
\end{abstract}

RESUMO

PALAVRAS-CHAVE: licenciamento ambiental, implantação florestal, política ambiental

\section{DIAGNOSTIC OF REFORESTATION PROJECT IN PARA STATE THE PERIOD 20082012}

\begin{abstract}
This study aimed to diagnose the licensing situation and demand Reforestation Projects filed with the Secretary of State for the Environment and Sustainability (SEMAS) from 2008 to 2012. We conducted a survey of all Reforestation Project protocoled during this period through the SEMAS, gathering data from the state of Para division in six sub-regions: Lower Amazon, Marajó, Metropolitan Region of Belém, Northeast of Pará and Southeastern of Pará and for municipalities. From
\end{abstract}


January, 2008 to December, 2012, were licensed a total of 312 Reforestation Project, distributed in 57 municipalities of Pará. Among this six sub-regions of Pará State, the sub-region of Southeastern of Pará was the one with the biggest demand $(67,31 \%)$, accounting for 210 licenses in this period. Among the 57 municipalities that required for Reforestation Projects, only seven municipalities showed demand of not less than ten reforestation projects licensed between 2008 and 2012 . The city with the biggest number of LAR's emitted was Dom Eliseu, located in the sub-region of Southeastern of Pará.

KEYWORDS: environmental licensing, forest implantation, environmental policy

\section{INTRODUÇÃO}

O setor florestal desempenha uma função importante na economia brasileira, contribuindo com uma parcela significativa na geração de produtos, tributos, empregos e renda. O setor é estratégico no fornecimento de matéria prima para 0 desenvolvimento da indústria de base florestal nacional (VIRGENS et al., 2015).

$\mathrm{Na}$ Amazônia, segundo HOMMA (2011), as possibilidades de reflorestamento para a produção de madeiras nobres, compensados, carvão vegetal, celulose e energia, podem constituir uma grande opção futura, substituindo a totalidade do atual extrativismo madeireiro e de manejo florestal. Para isso seria incorporada a recuperação de ecossistemas destruídos e a compensação ambiental, com espécies nativas ou exóticas, servindo para reflorestar áreas que não deveriam ter sido desmatadas e impróprias para atividades agrícolas, gerando renda e emprego.

Reconhecendo os serviços ecossistêmicos prestados pelas florestas e outras formas de vegetação nativa, a legislação florestal brasileira determina a delimitação das Áreas de Preservação Permanente (APP) - onde não se admite uso antrópico e a manutenção, em todas as propriedades rurais, de áreas como Reserva Legal (RL) com espécies nativas - onde se permite exploração sustentável (FASIABEN et al., 2011). O Estado do Pará é particularmente promissor para reflorestamentos por possuir 20 milhões de hectares de áreas abertas pela pecuária extensiva e agricultura itinerante em diferentes estágios de degradação, onde o reflorestamento pode atuar na sua recuperação e suprir o mercado consumidor com madeira de boa qualidade (IDEFLOR, 2010).

O reflorestamento é um segmento produtivo importante para o Estado do Pará, pois por meio dele pode-se promover a redução da pressão sobre as florestas nativas, mediante a recuperação de áreas degradadas e a possibilidade de gerar créditos de carbono. Tal necessidade se refere tanto às questões ambientais, quanto para atender ao objetivo de promover o desenvolvimento sustentável (ALMEIDA et al, 2011).

Nesse contexto, a SEMAS é responsável por emitir a Licença de Atividade Rural (LAR), onde em 2011, o Decreto 216 (art. $6^{\circ}, \S 4^{\circ}$ ) conferiu à LAR status de instrumento de controle, monitoramento e comprovação da regularidade ambiental das atividades nos imóveis rurais, em especial quanto a manutenção ou regularização das áreas de preservação permanente (APP) e de reserva legal (RL) (WHATELY, 2014).

Devido à descentralização, nos últimos anos, do licenciamento ambiental nos municípios do Pará, para as Unidades Regionalizadas (UREs), objetivou-se avaliar a situação do licenciamento e demanda dos Projetos de Reflorestamento protocolados na SEMAS (Secretaria de Estado de Meio Ambiente e sustentabilidade) no período de 2008 a 2012. 


\section{MATERIAL E MÉTODOS}

O estudo foi compreendido a partir da divisão do estado do Pará em seis mesorregiões (Figura 1): Baixo Amazonas, Marajó, Metropolitana de Belém, Nordeste Paraense, Sudoeste Paraense e Sudeste Paraense. Sendo realizado um levantamento de todos os Projetos de Reflorestamento protocolados no período de 2008 a 2012 na SEMAS/PA, localizada no município de Belém, Pará.

Os dados sobre a obtenção da Licença Ambiental Rural (LAR) dos projetos de reflorestamento foram obtidos a partir do software SIMLAM - Sistema Integrado de Monitoramento e Licenciamento Ambiental, em seguida foram agrupados por mesorregiões e municípios, e posteriormente foram submetidos à análise estatística descritiva.

O sistema supracitado possui um banco de dados abastecido com todos os dados dos projetos de reflorestamento protocolados e aprovados pela SEMAS.

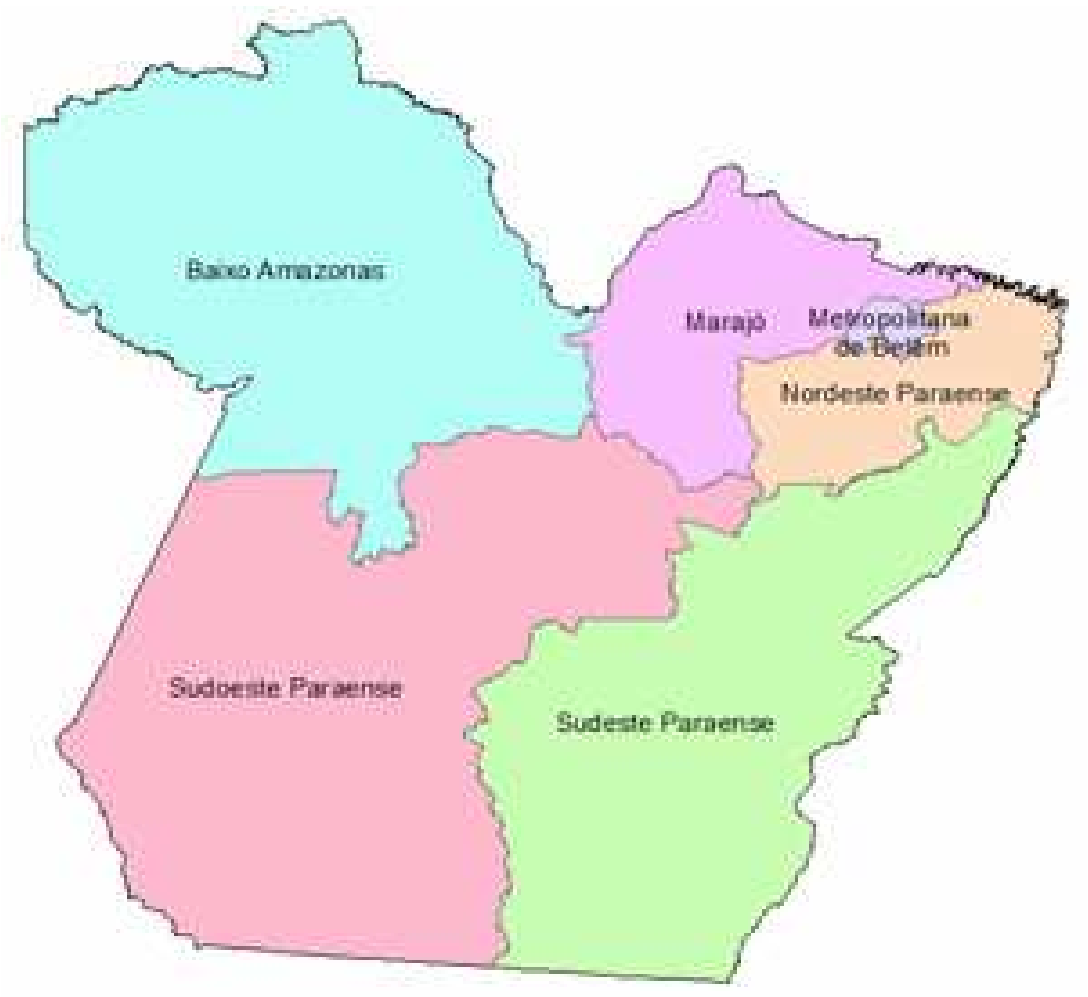

FIGURA 1: Mesorregião do Estado do Pará.

FONTE: IBGE. Adaptado: Renata Tenório.

\section{RESULTADOS E DISCUSSÃO}

Um total de 312 licenças de projetos de reflorestamento havia sido solicitado no período de 2008 a 2012. Considerando as seis mesorregiões do Estado do Pará, constatou-se que dos 57 municípios que demandaram licenças nesse período, 67,31\% pertencem à Mesorregião Sudeste Paraense representada por 210 LAR's; 24,68\% ao Nordeste Paraense com 77 LAR's; 3,85\% ao Sudoeste Paraense com 12 LAR's; 2,24\% à Mesorregião Metropolitana de Belém com 7 LAR's; 0,64\% ao Baixo Amazonas com 2 LAR's e 1,28\% ao Marajó contabilizando 4 LAR's (Tabela 1). 
TABELA 1- Demanda total por Projetos de Reflorestamento licenciados pela SEMAS no período de 2008 a 2012.

\begin{tabular}{ccc}
\hline \multirow{2}{*}{ Mesorregião } & \multicolumn{2}{c}{ LAR's demandadas } \\
\cline { 2 - 3 } & № & $\%$ \\
\hline Sudoeste do Pará & 12 & 3,85 \\
Baixo Amazonas & 2 & 0,64 \\
Nordeste Paraense & 77 & 24,68 \\
Sudeste Paraense & 210 & 67,31 \\
Marajó & 4 & 1,28 \\
Metropolitana de Belém & 7 & 2,24 \\
\hline Total & $\mathbf{3 1 2}$ & $\mathbf{1 0 0}$ \\
\hline
\end{tabular}

FONTE: SIMLAM, 2013.

A mesorregião Sudeste Paraense foi a que apresentou a maior demanda (67,31\%). Segundo ALMEIDA (2011), o segmento florestal nessa mesorregião tem crescido na área de silvicultura de florestas plantadas, mais especificamente, por meio de projetos de reflorestamento, onde os principais motivos são as necessidades de auto abastecimento a médio e longo prazos e a reposição florestal para atendimento das leis ambientais (no meio empresarial). Em relação aos produtores familiares, a atividade está mais relacionada à necessidade de investimento para o futuro da família.

As mesorregiões nordeste e sudeste do Estado do Pará se destacam pelo crescimento da demanda por carvão vegetal visando atender os fornos de beneficiamento de minérios, principalmente o ferro gusa (MATOS et al., 2012).

A menor demanda na mesorregião do Baixo Amazonas (0,64\%) pode ser explicada, de acordo com SCHNEIDER et. al (2000), pela redução dos recursos florestais do Nordeste e Sudeste Paraense que fez com que muitas empresas madeireiras, que não entraram no mercado de reflorestamento, migrassem para as ricas florestas do Baixo Amazonas e Sudoeste Paraense, onde ainda há forte exploração de florestas primárias. Essa migração também está relacionada com a BR-163, rodovia que liga Cuiabá-MT à Santarém-PA, considerada um grande eixo de escoamento de madeira na Amazônia.

AMORIM et al. (2011) verificaram que a madeira serrada, compensados e os laminados são advindos $100 \%$ de espécies nativas do Pará, havendo uma falta de interesse na comercialização de florestas plantadas. Os autores relatam que os fatores que podem influenciar a utilização da madeira oriunda de florestas nativas são: a falta de tecnologia para produzir madeira de boa qualidade em florestas plantadas, a cultura da população local e a estética das madeiras.

No período avaliado, os anos de 2009 e 2010 foram os que apresentaram maiores demandas (68 e 134, respectivamente), sendo o Sudeste Paraense o mais representativo no ano de 2010 , com $75,37 \%$ (Tabela 2 ).

Em 2010 houve o maior índice de aprovação de Projetos de Reflorestamento. No contexto da época, existiam fortes pressões do setor produtivo para a liberação de matéria-prima florestal legal. Com isso, a gestão da SEMAS-PA adotou alguns ENCICLOPÉDIA BIOSFERA, Centro Científico Conhecer - Goiânia, v.11 n.22; p.3751 2015 
procedimentos que flexibilizaram o licenciamento, por meio de emissão de LAR. A meta da SEMAS era atingir uma média que representasse o potencial florestal do Estado do Pará.

TABELA 2- Demanda anual por Projetos de Reflorestamento licenciados pela SEMAS no período de 2008 a 2012.

\begin{tabular}{|c|c|c|c|c|c|c|c|c|c|c|}
\hline MESORREGIÃO & № & $\begin{array}{c}2008 \\
(\%)\end{array}$ & № & $\begin{array}{c}2009 \\
(\%)\end{array}$ & № & $\begin{array}{c}2010 \\
(\%)\end{array}$ & № & $\begin{array}{c}2011 \\
(\%)\end{array}$ & № & $\begin{array}{c}2012 \\
(\%)\end{array}$ \\
\hline Sudoeste & 0 & 0 & & 4,41 & & 2,99 & 4 & 9,09 & 1 & 4 \\
\hline & & 0 & & 2,9 & & 0 & & & & \\
\hline & 10 & 24,39 & 17 & 25 & 28 & 20,9 & 13 & 29,55 & 9 & 36 \\
\hline Sudeste Paraense & 28 & 68,29 & 44 & 64,71 & $\begin{array}{c}10 \\
1\end{array}$ & 75,37 & 22 & 50 & 15 & 60 \\
\hline & 1 & 2,44 & 0 & 0 & 0 & 0 & 3 & 6,82 & 0 & 0 \\
\hline $\begin{array}{r}\text { Metropoli } \\
\text { Belé }\end{array}$ & 2 & 4,88 & 2 & 2,94 & 1 & 0,75 & 2 & 4,55 & 0 & 0 \\
\hline Cotal & 41 & 100 & 68 & 100 & 134 & 100 & 44 & 100 & 25 & 100 \\
\hline
\end{tabular}

FONTE: SIMLAM, 2013.

No período de janeiro de 2008 a dezembro de 2012, foi licenciado um total de 312 Projetos de Reflorestamento, distribuídos em 57 municípios do Estado do Pará. Os municípios que apresentaram representatividade igual ou superior a dez projetos licenciados (Figura 2) estão distribuídos em ordem decrescente: Dom Eliseu (68), Paragominas (27), Ulianópolis (18), Rondon do Pará (17), Tomé-Açu (16), Itupiranga (15) e Moju (10).

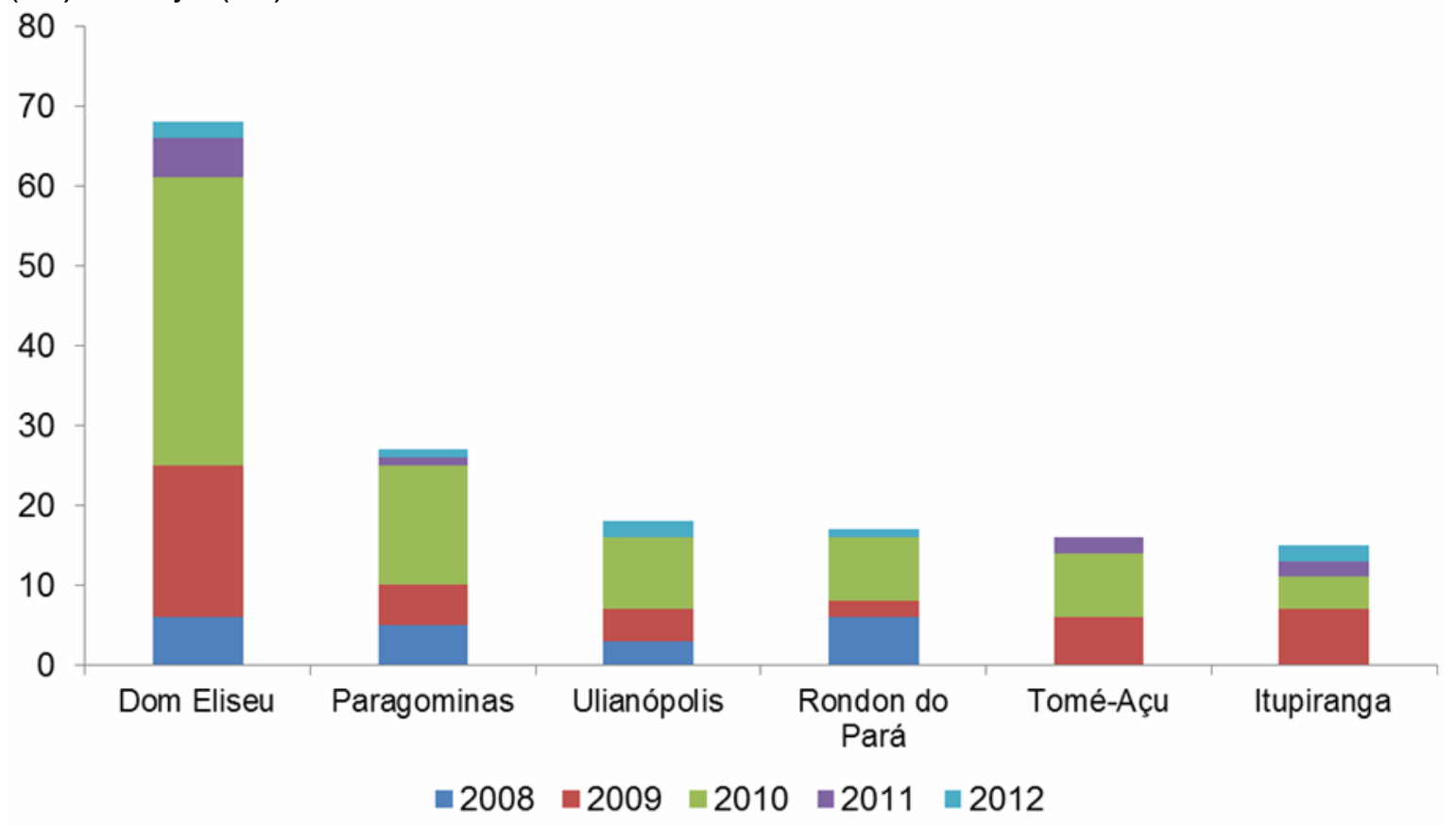

FIGURA 2 - Municípios que obtiveram demanda, no período de 2008 a 2012, igual ou superior a 10 LAR's.

FONTE: SIMLAM, 2013. 
A representatividade de Dom Eliseu pode ser explicada pela declaração da RESOLUÇÃO COGES/PMV № 07/2012 do Programa Municípios Verdes, o qual declara que o município está apto a receber vários benefícios previstos no programa. Destacam-se: a suspensão dos embargos administrativos ambientais efetuados nos imóveis rurais situados em seu território; prioridade no recebimento de recursos públicos, apoio e capacitação para o fortalecimento da gestão ambiental municipal, dentre outros que viabilizam o licenciamento de projetos florestais no município.

Atualmente, o município de Dom Eliseu está concorrendo ao Selo Verde do Conselho Brasileiro de Manejo Florestal - FSC, em função da parceria firmada, em 2009, entre a Superintendência da Amazônia - Sudam e a prefeitura de Dom Eliseu. Houve a implantação na cidade de um projeto de reflorestamento para recuperação de áreas degradadas pelas atividades madeireiras; por meio do plantio de mudas florestais, frutíferas e cultura de subsistência (SUDAM, 2013).

O município de Paragominas ganha destaque no processo de reflorestamento, uma vez que seu histórico de ocupação agropecuário gerou uma grande quantidade de áreas degradadas, fazendo com que o plantio de espécies florestais surja como uma alternativa à recuperação do potencial produtivo dessas áreas e uma atividade econômica de base florestal (PINTO, et al., 2009).

Quanto a menor demanda de licenças aprovadas de projetos de reflorestamento do município de Moju, pode ser explicado por meio dos dados do IMAZON (2010) que relata que município está inserido na lista crítica do Ministério do Meio Ambiente. Portanto, não recebe os benefícios desse ministério para otimizar a analise dos projetos florestais e consequentemente suas licenças.

No entanto, de acordo com a Assessoria de Comunicação Social (Ascom) SEMAS (2013), o município participará do Ordenamento Ambiental, via o projeto de CAR coordenado pela Secretária Estadual de Meio Ambiente e pelo Programa Municípios Verdes. Será priorizado o Cadastro Ambiental Rural (CAR) em pequenas propriedades rurais, de até quatro módulos fiscais, visando assim viabilizar a aprovação de licenciamentos florestais.

\section{CONCLUSÃO}

Atualmente, os projetos de reflorestamento têm sido bastante incentivados para subsidiar atividades para fins energéticos, madeireiros, socioambientais, frutíferos, industriais ou outros, evitando dessa forma a pressão sobre as florestas nativas e recuperando áreas alteradas. A busca por leis que fortaleça a adequação ambiental tem sido objetivo de entidades governamentais, como a SEMAS, que obrigam os detentores das atividades com potencial poluidor ou que possa trazer riscos ao meio ambiente a fazer o Licenciamento Ambiental.

No caso do Estado do Pará, o licenciamento é fundamental na socioeconomia dos municípios e na prevenção do desmatamento; a presente pesquisa mostrou que houve um aumento significativo, no período de 2009 e 2010, no número de pessoas jurídicas que buscam o Licenciamento Ambiental. Isso implica em dizer que está crescendo o processo de conscientização por parte dos empreendedores e da efetividade da atuação do órgão competente pelo monitoramento do uso dos recursos naturais. Contudo, a falta de subsidio financeiro, principalmente, para pequenas empresas ainda permiti um número expressivo de áreas de reflorestamento não cadastradas e regularizadas.

Neste caso, o levantamento de projetos de reflorestamento que demandaram licenças no Estado do Pará permite inferir sobre a dinâmica anual de licenciamento 
da SEMAS nos municípios e subsidiar programas, como por exemplo o Programa Municípios Verdes (PMV).

\section{REFERÊNCIAS}

ALMEIDA, L. S. de; COUTINHO, C. H. O; SANTANA, A. C. de. Perspectivas para o reflorestamento no estado do Pará a partir do uso da terra no nordeste e sudeste paraense. Amazônia: Ciência \& Desenvolvimento, v.7, n.13, p. 16, 2011.

AMORIM, J. da S.; SANTOS NETO, A. P.; SILVA, G. C.; FERREIRA, J. S. Caracterização da atividade comercial madeireira desde a origem da matéria-prima até a geração de resíduos em Itapetinga - BA. Enciclopédia Biosfera, v.7, n.12, p.1-8, 2011.

FASIABEN, M. do C. R.; ROMEIRO, A. R.; PERES, F. C.; MAIA, A. G. Impacto econômico da reserva legal sobre diferentes tipos de unidades de produção agropecuária. Revista de Economia e Sociologia Rural, v.49, n.4, p. 1051-1096, 2011.

HOMMA, A. K. O. Madeira na Amazônia: extração, manejo ou reflorestamento?. Amazônia: Ci. \& Desenv., v. 7, n. 13, p.147-161, 2011.

IDEFLOR - Instituto de Desenvolvimento Florestal do Estado do Pará. Plano safra florestal madeireira do Estado do Pará: 2010. Belém: IDEFLOR, 2010. 102p.

IMAZON - Instituto do Homem e do Meio Ambiente da Amazônia. Fatos Florestais da Amazônia. Belém - PA, 2010. Pág. 126.

MATOS, G. S. B.; SILVA, G. R. G.; PIEDADE, M. A.; SILVA, R.; ROCHA, J. E. C. Desenvolvimento inicial e estado nutricional de clones de eucalipto no nordeste do Pará. Acta Amazônica, v.42, n. 4, p. 491-500, 2012.

PINTO, A.; AMARAL, P.; SOUZA, J.R.; VERÍSSIMO, A.; SALOMÃO, R.; GOMES, G.; BALIEIRO, C. Diagnóstico socioeconômico e florestal do município de Paragominas. Relatório técnico, Belém, Pará. Instituto do homem e meio ambiente da Amazônia - IMAZON, 2009. 65 p.

SEMAS - Secretaria de Estado de Meio Ambiente e Sustentabilidade. Disponível em: <http://www.semas.pa.gov.br/2013/08/28/moju-recebe-gestao-ambiental-plenae-lanca-projeto-car/>. Acesso em: 30 de agosto de 2013.

SUDAM - Superintendência do Desenvolvimento da Amazônia. Disponível em: <http://www.sudam.gov.br/comunicacao-social/619-com-a-parceria-da-sudammunicipio-de-dom-eliseu-pode-ganhar-selo-verde>. Acesso em: 03 de setembro de 2013.

VIRGENS, A. P. das; FREITAS, L. C.; LUZ, D. S.; MOREIRA, A. C. D. Análise Econômica e de sensibilidade em Projetos de Reflorestamentos no Estado da Bahia Enciclopédia Biosfera, v.11, n.21, p.120-147, 2015. 
SCHNEIDER, R.; ARIMA, E.; VERÍSSIMO, A.; BARRETO, P.; JÚNIOR, C. S. Amazônia Sustentável: Limitantes e oportunidades para o desenvolvimento rural. Banco Mundial//mazon. Brasília/Belém, 2000. 58 p.

WHATELY, M. Passo a passo para licenciamento de atividades rurais. Série Gestão Ambiental Municipal Para a Area Rural, v.2, p. 11-79, 2014. 